\section{Richard Ropner}

Formerly Consultant

Psychiatrist,

Gloucestershire

\section{Partnership NHS Trust}

Richard (Dick) Ropner was born on 13 April 1941 in Edinburgh, where he was to study medicine; he graduated in 1965. Before entering psychiatry he gained a wide range of clinical experience, which included a year as an intern in the USA, working as a doctor in Nigeria (where he had to flee when Biafran troops invaded Western Nigeria) and, later, assisting in general practice in Norfolk and Guernsey.

Dick's psychiatry training began at St Pancras Hospital, and then continued on the Oxford Psychiatric Rotational Training Scheme. He obtained the DPM in 1972 and after doing locum work at Broadmoor Hospital, he became a consultant in Gloucestershire, where he worked for the rest of his professional life.

Dick made wide contributions to psychiatry locally. He developed the alcohol treatment service and was involved in the planning of and the move to community-based services. He had an

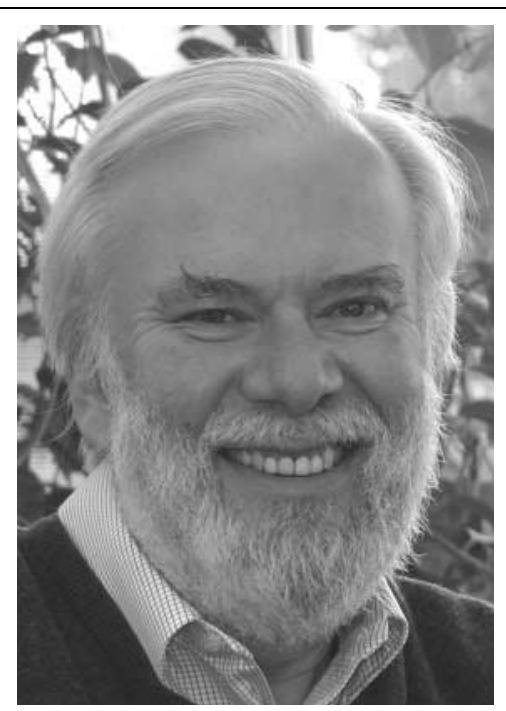

interest in psychosocial medicine, gave psychiatric advice to the local alcohol clinic, and established a gender dysphoria clinic.

In recent years he was chair of the local medical staff committee, a role he continued until 2 weeks before his death. He was also one of the local 'Wise Men' and provided treatment and care to local clinical staff with emotional problems.
All who trained or subsequently worked with Dick would agree that he was a most interesting psychiatrist, often expressing views which challenged current dogma. Local clinicians will remember him not only for his caring approach to patients but also for his ability to capture the essence of his patients' problems and circumstances, and to relay this in highly colourful prose. Dick's many friends will remember him for his quirky humour, the way he loved to pull their legs with disarming seriousness, accompanied by a characteristic wink, and, most of all, for his good nature, warmth and generosity.

Some months ago Dick was diagnosed as suffering from pancreatic cancer, but despite this, he continued to live life to the full, yet with a calm acceptance of the inevitable outcome.

The wide affection felt for Dick was reflected in the very large congregation, including former patients, who attended the service to celebrate his life.

He leaves his much loved family - his wife Janet (a consultant haematologist), a son, James (a general practitioner registrar) and a daughter Victoria (a lawyer). Dick's first grandchild was born 2 months after his death.

Keith Hawton

\title{
reviews
}

\section{Reading about books on passing MRCPsych exams}

I recommend Pass the MRCPsych Parts I and II by Williams et al (2005) as a light read, accomplished in two sittings (one for the really committed). This book marks out the terrain of the exams, including the potholes, and offers pragmatic advice and helpful tips. Concluding the brief text is a sobering chapter 'If at first you don't succeed...' which I found somehow makes 'the beast' seem less ferocious. However, it is not a textbook or a revision aide. It is a good book to buy for a study group, but would be less valuable for the individual.

Examination Notes in Psychiatry Basic Sciences by Mahli \& Mahli (2005) is a deceptively small book which I found useful and which covers everything you might require for part I but may not be enough for part II. The text is dense and reading it can be demanding. Quite a few chapters are organised in bullet form, including ones on neurochemistry and neuropharmacology. These can be cumbersome. The book has no references, so I struggled to find the matter authoritative.
MRCPsych Parts I and II: Individual Statements and EMI Practice Exams by Sauer (2005) is another addition to that long list of MCQ books that inevitably become the precious possessions of every senior house officer sitting the exams. We buy them all and we don't need much persuasion. However, Sauer is better than quite a few out there. The answers are accompanied by short explanations that are to the point. I found a few really instructive answers, and so will you.

By and large, one doesn't realise the importance of the clinical aspect of the exam until the theoretical part is over. Preparation for the clinical exam is usually reserved for later. MRCPsych Part 1: Passing the OSCE by O'Gara \& Sauer (2005) presents eight exam sessions. Each is then explained with a grey box at the end, highlighting what can be done for extra marks. An excellent book, as long as you read it completely. It would be unwise to pick and choose from such short texts.

Patient Management Problems in Psychiatry by Olumoroti \& Kassim (2005) also focuses on the clinical exams, and is detailed and exhaustive. A plan for patient management problems is provided for every question, with detailed answers following. The book also attempts to explain a bored examiner's train of thought and where, as a result, his questions may lead (no wonder the 500 pages). It provides buzz words and references, and is valuable for revision.

So, where does this leave the weary traveller? Changing jobs every 6 months is harrowing enough. The Membership exams seem the final hoop. No wonder the anxiety. Perhaps we can better prepare for them and improve the experience, but I don't think the apprehension will ever go away.

MAHLI, G. S. \& MAHLI, S. (2005) Examination Notes in Psychiatry - Basic Sciences. Hodder Arnold.

O'GARA, C. \& SAUER, J. (2005) MRCPsych Part 1: Passing the OSCE. Hodder Arnold.

OLUMOROTI, O. J. \& KASSIM, A. A. (2005) Patient Management Problems in Psychiatry. Elsevier.

SAUER, J. (2005) MRCPsych Parts I and II: Individual Statements and EMI Practice Exams. Hodder Arnold.

WILLIAMS, C. J.TRIGWELL, P. \& YEOMANS, D. (2005) Pass the MRCPsych Parts I \& II (3rd edn). Elsevier.

Muzaffar Husain South London and Maudsley NHS Trust, email: muzaffar.husain@iop.kcl.ac.uk 